\title{
Exploring Self-Management of Adults Living with HIV on Antiretroviral Therapy in North-West Ethiopia: Qualitative Study
}

This article was published in the following Dove Press journal: HIVIAIDS - Research and Palliative Care

\author{
Habtamu Areri (iD) ${ }^{1,2}$ \\ Amy Marshall (D)' \\ Gillian Harvey (D)
}

'Adelaide Nursing School, Faculty of Health and Medical Sciences, The University of Adelaide, Adelaide, SA 5005, Australia; ${ }^{2}$ School of Nursing and Midwifery, College of Health Sciences, Addis Ababa University, Addis Ababa 44I2, Ethiopia
Correspondence: Habtamu Areri

Tel +251910218513

Email habera76@gmail.com
Background: The changing nature of HIV from an acute to chronic illness requires adults living with HIV to self-manage. Self-management enables individuals with HIV to maintain physical health, medication adherence and live with HIV-related conditions. This study aimed to explore self-management experiences of adults living with HIV on antiretroviral therapy in Ethiopia.

Methods: A qualitative descriptive study framed by the Individual and Family SelfManagement Theory was carried out to explore the self-management experience of adults living with HIV in Northwest Ethiopia. Eleven semi-structured, in-depth interviews were conducted. The recruitment involved participants who volunteered to be contacted during a preceding quantitative study. The interview data were coded inductively and subject to thematic analysis. Results: The main themes identified, each with a number of sub-themes, related to perceptions and experience of self-management, barriers and facilitators of self-management. Factors influencing self-management behaviour were inter-connected and particularly influenced by spiritual practices, low levels of income and experiences of stigma and discrimination.

Conclusion: The study highlights barriers to self-management among individuals living with HIV on antiretroviral therapy in a resource-constrained country. Interventions to address modifiable barriers and build on identified facilitators of self-management include working with the broader community to minimise HIV-related stigma and discrimination and engaging with religious leaders to tackle the observed conflict between spiritual practice and effective self-management behaviour.

Keywords: self-management, barriers, facilitators, antiretroviral therapy, stigma ; discrimination

\section{Introduction}

In Eastern and Southern Africa, over 20.6 million people were living with HIV in 2018, including 690000 people living with HIV in Ethiopia. ${ }^{1}$ The government of Ethiopia has a clear policy to improve access to medication, and the national Antiretroviral Therapy (ART) coverage has increased. However, living with HIV remains a challenging condition due to stigma, discrimination, poverty, and a low educational literacy rate. ${ }^{2}$

Improvements in HIV treatment have changed the experience of living with HIV from an acute to a chronic condition, which requires the individual with HIV to learn to live with and manage their condition. This implies that adults living with HIV (ALWHIV) should practice self-management (SM) to address the unique symptoms, medical challenges, and psycho-social stressors that they face daily. ${ }^{3}$ Effective SM requires the individual to routinely take care of themselves and 
illness-specific concerns, supported by families, social networks, and HIV care providers. ${ }^{4-6}$ This can help to optimise the physiological, psychological, and social functioning of ALWHIV and enables them to take an active role in their health care decision-making.

In order to support ALWHIV, interventions aimed at enhancing SM are viewed as essential. ${ }^{7}$ According to Holtzman, Brady and Yehia, ${ }^{8}$ the most common interventions to improve SM are counselling about the benefits of medication adherence and how to live with HIV. Our systematic review also identified common effective interventions to enhance SM which consisted of SM skills training, counselling, provision of symptom management manuals, and technology-assisted support through phone calls, text messaging and online support. ${ }^{7}$ As such, support from HIV care providers is crucially important in improving the wellbeing of ALWHIV. ${ }^{9,10}$ HIV disclosure is another key aspect of HIV care and treatment, as it helps to initiate and mobilise support, decrease fear of stigma and discrimination and improve self-efficacy. ${ }^{11}$

Despite the literature recommending various strategies to promote SM, there is relatively little empirical research examining the SM experiences of ALWHIV on therapy. Where studies have been undertaken, it appears that selfmanagement experiences and the factors that influence SM are variable. ${ }^{9}$ A survey conducted in the USA indicated that ALWHIV used sleeping and support groups to enhance SM, as well as paying attention to diet management and physical activities. ${ }^{12}$ In comparison, a study conducted in Uganda identified that ALWHIV depended on health system resources to improve their knowledge of the disease and coping skills for better self-management. ${ }^{9}$ Evidence is lacking to better understand the SM experiences of ALWHIV on therapy in Ethiopia. This is particularly important given the additional challenges faced by ALWHIV in resource-limited settings, where the health system infrastructure is less developed, literacy levels are low, and individuals are more likely to face financial difficulties. ${ }^{9,13,14}$ Skipping medication for religious reasons is another challenge that has been identified in some studies. ${ }^{15,16}$ These are all factors that could impact on selfefficacy $^{17,18}$ and the individual's ability to selfmanage. ${ }^{11,12,19-21}$ This study set out to explore these issues and other related factors, building upon a prior survey undertaken in a region of Ethiopia to assess SM amongst ALWHIV. The survey findings revealed low levels of SM amongst the population studied. Predictors of SM included gender, literacy, living area, awareness of own HIV condition, self-efficacy, the use of reminder strategies, and encouragement to disclose HIV status. ${ }^{22}$

\section{Methods}

\section{Design and Study Setting}

As the second phase of a sequential explanatory mixedmethods study, a qualitative descriptive approach was applied to gain an in-depth understanding of the survey findings. ${ }^{22}$ The study was conducted in Debre Markos referral hospital, which is the only referral hospital in East Gojjam of Amhara regional state, from September 1 to October 30 2019. The setting was selected as it is the major referral hospital serving a population of over 3.6 million.

\section{Participant Recruitment}

The study included adults ( $\geq 1$ 18years) living with HIV on ART for at least 6 months. The study excluded those unable to respond for any reasons such as illness or inability to communicate, and those who did not volunteer to participate. An invitation letter was posted during the survey data collection to invite participants to take part in an in-depth interview. Twenty participants showed interest and contacted the first author [HA] to register their willingness to be interviewed. From the potential pool of 20 interviewees, participants were purposively selected to ensure balanced representation, for example, in terms of gender and area of residence (urban-rural). A criterion of data saturation was applied to determine the final sample size. ${ }^{23}$ This was achieved after the first eleven interviews, at which point no new data were identified, and it was deemed that data saturation had been reached.

\section{Data Collection}

A semi-structured interview guide was developed, informed by the survey findings and the theoretical framework that guided the overall study, namely the Individual and Family Self-Management Theory (IFSMT). The IFSMT is a descriptive middle-range theory, comprising interrelated dimensions defined as contextual factors, the process of SM, SM interventions and SM outcomes. The contextual factors include condition-specific factors, physical and social environment, and individual factors. The process of self-management is influenced by the individual's knowledge and self-efficacy, self-regulation abilities, and social facilitation, such as support and collaboration. SM interventions are actions that enable the process of SM and SM 
outcomes and include counselling, education and training, encouraging disclosure of HIV status and linking to support groups. SM outcomes encompass physical health, engagement in medication management, mobilisation of resources, coping and living with $\mathrm{HIV}^{5}$

The interview guide was constructed in line with the theoretical domains of the IFSMT and then pre-tested before the main data collection began. The interviewer (HA) had prior experience of undertaking qualitative research and conducted the pre-test on two purposively selected ALWHIV to check the clarity of the interview guide. Minor changes were made to the interview guide following these interviews (Table 1). The pre-test data were not included in the analysis. The purpose of the study, the procedure of the in-depth interview and a request to audiotape the interview were explained to the participants before beginning the interview process. The participants were then asked to sign a written consent for their participation and the use of the audio recording. The first author [HA] conducted face-to-face interviews using the semi-structured interview guide to ensure consistency. The interview was carried out in private in the adherence counselling room, where participants received their usual counselling service, in the local language (Amharic).

Eleven participants (six females and five males) were interviewed and included in the final analysis. One participant stopped the interview and withdrew without justifying a reason, and the data were not used in the analysis. The interview time ranged from 25 to 45 minutes. Upon completion of the interview, the conversation was summarised for the participant to confirm the content of the discussion. At the end of the interview, participants were compensated for their time with 60ETB. The audio-recorded interview was transcribed verbatim and read while listening to the audio recording to check the accuracy of the data.

\section{Data Analysis}

The interview data were translated from local Amharic language to English by a language expert before the final analysis. Interview data were imported into the qualitative analysis package QSR Software NVIVO 12. Respondents were coded as participant/P1, 2, 3, through to 11 to maintain anonymity. The process of analysis was conducted according to Braun and Clark's thematic analysis approach, ${ }^{24}$ namely: 1) Familiarisation with the data; 2) Generating initial codes; 3) Searching for themes; 4) Reviewing the themes; 5) Defining and renaming the themes; 6) Producing the final report. The first author read and immersed himself in the data before preliminary analysis, keeping memos for later checking and use. To enhance the trustworthiness of the findings, three interview transcripts were coded independently by all three authors and discussed to identify and resolve any discrepancies in coding. After reaching an agreement, the first author [HA] completed the initial coding of the remaining transcripts. Emerging codes and themes were critically discussed and confirmed through regular meetings of the project team [HA, AM and $\mathrm{GH}]$.

\section{Results}

Most of the participants were aged 35 to 60 years (see Table 2), and around half had completed some level of education. All of the participants were Orthodox Christian by religion, which is a dominant religious practice in Ethiopia. Their monthly income ranged from 120-6360ETB (4.30-227USD). All participants had been receiving ART for between 5 and 15 years. Three main themes, with related sub-themes, were

Table I Semi-Structured Interview Guide: Short Form

\begin{tabular}{|c|c|}
\hline \# & Interview Guide \\
\hline I & Sociodemographic characteristics \\
\hline 2 & What does the term self-management (SM) mean to you? \\
\hline 3 & What factors are hindering/facilitating your SM? \\
\hline 4 & $\begin{array}{l}\text { Is this health facility convenient for your HIV care and } \\
\text { treatment? }\end{array}$ \\
\hline 5 & $\begin{array}{l}\text { How do you rate your self-efficacy/confidence for the SM } \\
\text { program? }\end{array}$ \\
\hline 6 & $\begin{array}{l}\text { What kind of social facilitation/support have you received for } \\
\text { your HIV-related SM? }\end{array}$ \\
\hline 7 & $\begin{array}{l}\text { How do you see your overall self-regulation abilities? How do } \\
\text { you manage your HIV illness-related symptoms? What is your } \\
\text { goal of HIV treatment? }\end{array}$ \\
\hline 8 & $\begin{array}{l}\text { Can you tell me about the interventions provided to you to } \\
\text { support/enhance your SM? } \\
\text { SM behaviour }\end{array}$ \\
\hline \multirow{5}{*}{9} & $\begin{array}{l}\text { a. Can you tell me how, on a daily basis, you self-manage your } \\
\text { physical health? Symptoms? Side effects? Diet? Stress? What } \\
\text { helps/prevents you from performing your HIV related phy- } \\
\text { sical health practice? }\end{array}$ \\
\hline & $\begin{array}{l}\text { b. Have you mobilised existing support (families, HIV networks } \\
\text { and health care providers) around you for your SM? }\end{array}$ \\
\hline & c. What do you feel about living with chronic HIV conditions? \\
\hline & What do you think could be the impact of ART on your life \\
\hline & Are you taking medication for HIV as recommended? \\
\hline 10 & $\begin{array}{l}\text { What do you think is the biggest challenge in your ART } \\
\text { program and/or SM overall? What has worked well? What do } \\
\text { you suggest as a solution to improve SM of ALWHIV on ART? }\end{array}$ \\
\hline I I & Any additional points? \\
\hline
\end{tabular}


Table 2 Demographic Characteristics

\begin{tabular}{|l|l|l|}
\hline Demographic & & Number of Participants \\
\hline Age group (in years) & $35-60$ & 9 \\
& $>60$ & 2 \\
\hline Gender & Male & 5 \\
& Female & 6 \\
\hline Marital status & Never married & 1 \\
& Married & 4 \\
& Divorced & 2 \\
& Widowed & 4 \\
\hline Living area & Rural & 5 \\
& Urban & 6 \\
\hline \multirow{2}{*}{ Educational level } & No education & 5 \\
& Grade I-12 & 4 \\
& Diploma & 1 \\
& Degree & 1 \\
\hline
\end{tabular}

identified from the inductive analysis, namely; Perceptions and experience of SM; Facilitators of SM; and Barriers to SM (see Table 3 and Figure 1).

\section{Perception and Experiences of Self-Management}

Participants typically described SM as a process of maintaining their health, with a particular focus on staying healthy, symptom management, reducing stress and medication

Table 3 Main Themes and Sub-Themes

\begin{tabular}{|c|l|l|}
\hline \# & Themes & Sub-Themes \\
\hline $\mathbf{I}$ & $\begin{array}{l}\text { Perceptions and experience of self- } \\
\text { management }\end{array}$ & $\begin{array}{l}\text { Staying healthy } \\
\text { Symptom management } \\
\text { Reducing stress } \\
\text { Medication taking } \\
\text { behaviour }\end{array}$ \\
\hline 2 & Facilitators of self-management & $\begin{array}{l}\text { Support mechanisms } \\
\text { Reliance on HIV care } \\
\text { providers } \\
\text { Acceptance of HIV } \\
\text { Availability of free HIV } \\
\text { medication }\end{array}$ \\
\hline 3 & Barriers to self-management & $\begin{array}{l}\text { Financial difficulties } \\
\text { Fear of stigma and } \\
\text { discrimination } \\
\text { Spiritual practice } \\
\text { Lack of trust in HIV care } \\
\text { providers }\end{array}$ \\
\hline
\end{tabular}

taking behaviour. The SM perceptions and experiences of respondents were summarised under four sub-themes.

\section{Staying Healthy}

Participants largely associated SM with a desire to stay healthy. This involved keeping themselves protected from disease and staying healthy, for example, by eating a proper diet, undertaking physical activity, performing personal hygiene and the use of a condom. Diet management and physical activity were the most commonly referred to practice by the respondents:

I eat my meal properly and on time. [P1]

I try to make my diet, fresh and complete. I am doing this to prevent infections. [P4]

I am trying to eat cooked food from different sources. [P2]

However, although participants were trying to eat a balanced diet, financial difficulties presented a challenge for many of them.

Inadequate income is affecting my diet management. [P1]

Participants of the study also reported engaging in different forms of physical activity to stay healthy, although this was often undertaken as part of a daily routine such as getting to and from work and involvement in manual labour:

I do physical exercise on a regular basis that makes me active and healthier. [P4]

Every day, I always walk for more than 20 minutes to work on foot. However, I do not have a planned schedule to do physical exercise. [P1]

However, around half of the interviewees [P 1, 2, 3, 6 and 10] noted that a lack of motivation and awareness was preventing them from performing planned physical activities.

\section{Symptom Management}

Most participants reported seeking medical advice when they experienced symptoms such as side effects of medication and tiredness. For less complicated issues, many of the participants described managing their symptoms by taking rest, sleeping or going to church to be baptised with Holy water.

When I felt a symptom of disease, I went to a health institution, but if the symptom is simple, I took a rest/ sleep. When I felt tired, I also took a rest. I also go to the monastery church for baptising through Holy water for headache and feeling sick. [P9] 


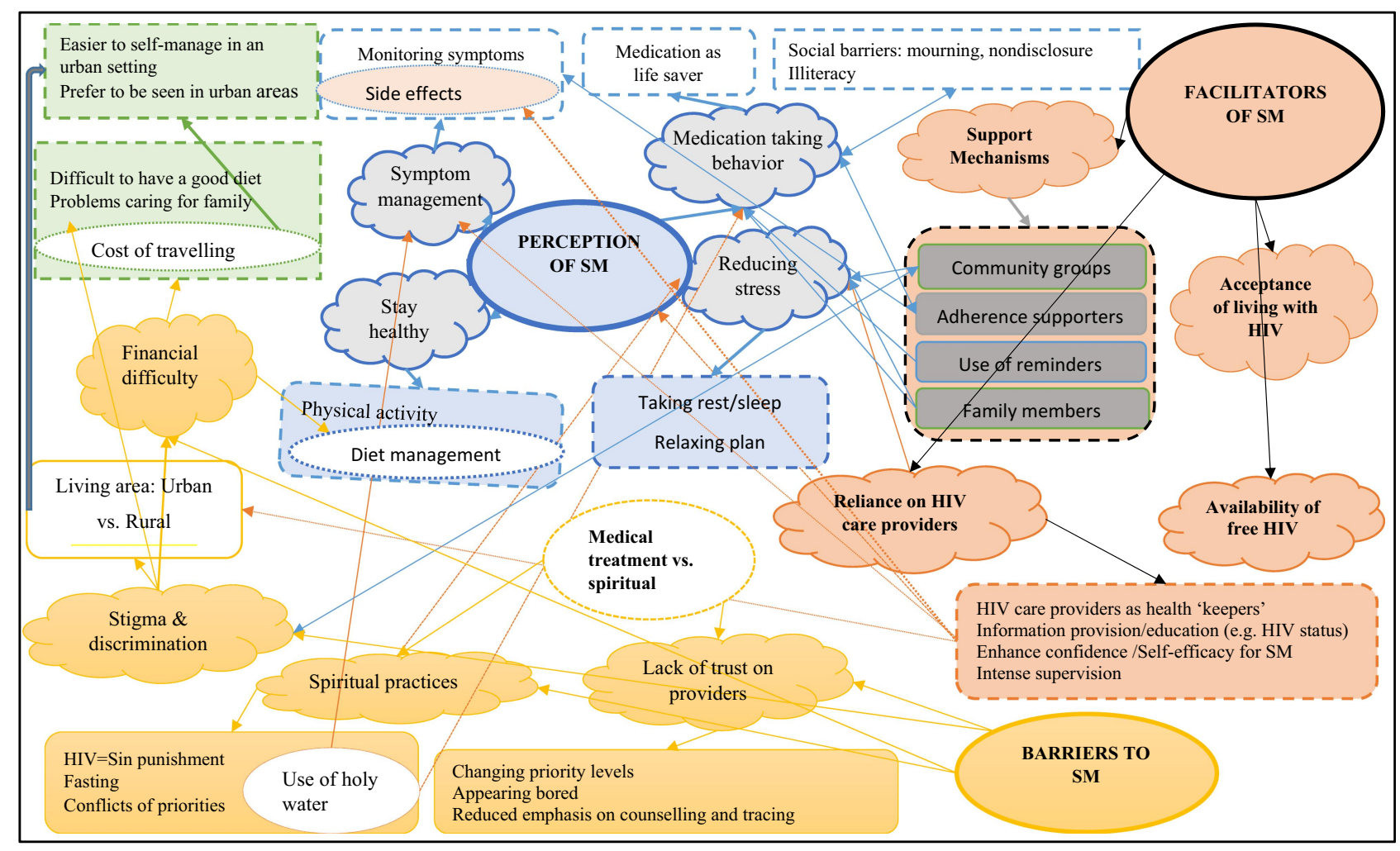

Figure I Concept coding.

Since I acclimatise with the disease, I try to find a remedy for mild disease symptoms ... I have sometimes got a headache problem, and for its management, I took coffee, but if not relieved, I contacted health care providers. Nevertheless, if the symptom of the disease seems complex, I go to health care organisations. I gave due attention to disease symptoms primarily. [P1]

In relation to medication, only two participants reported experiencing side effects [P4 \& 5], and both said they made use of adherence supporters and HIV care providers:

I had a side effect of drugs. For which, I consulted HIV care providers ... I frequently came here to get support from HIV care providers and adherence supporters of the hospital. [P4]

\section{Reducing Stress}

Most of the participants described experiencing some form of stress or worry related to their current situation. Various stress-reducing strategies were reported. These included seeking support from family and friends:

I am trying to relax sometimes with friends. [P6]

... because of stress, I am losing weight. I am worried about my child. I tried to relax, but it works for a short time. Sometimes, I share my stress with my friends and my families. [P1]

Other participants used sleeping or taking a rest as a strategy for reducing their experience of stress. However, the inadequacy of income posed a challenge for some participants in terms of relaxation time as they were forced to keep working and could not afford to take time off work.

\section{Medication Taking Behavior}

Participants agreed that taking their medication routinely was essential for improved health status and leading a productive life. As a result, most stated that they had not missed their medication in the last month. However, a number of the participants did not strictly follow the schedule of taking medication at the set time. This was for a number of reasons, particularly social and religious issues, such as fear of other people seeing them taking medication, fasting, forgetting and mourning.

Oh! I miss medication sometimes for different reasonsfear of others and forgetting to take medication. Sometimes, I leave the drug at home. Moreover, I do not have any person to remind me of taking medication. [P1] 
I did not take the drug one day because of mourning. The families did not allow me to return home, and I remained without medication for that night. [P7]

While in most cases taking medication was considered as "a deadly struggle for saving a life" [P2, 4,5,6,7 and 10], it was considered that medication should be appropriately taken to the end of life. Participants commented that taking medication on the days of fasting was challenging [P1, 8 and 9].

\section{Facilitators of Self-Management}

Four main facilitators of SM were reported by the participants related to their support mechanisms, a reliance on HIV care providers, acceptance of HIV, and the availability of free HIV medication.

\section{Support Mechanisms}

Adherence supporters [expert patients] are people living with HIV on ART who are trained and employed to support other people living with HIV. The presence of these supporters in HIV care and treatment clinics helps to enhance the sharing of experience and clarify potential misconceptions of other individuals living with HIV on ART. Adherence supporters were described as a lifesaver by many of the participants.

Adherence supporters were life-saving people from the starting time. They were helping me in providing information on when to come, how to manage if symptoms happen and clarifying my confusions. [P8]

Social networking and community groups were also seen to be helpful through enhancing engagement in treatment, sharing experiences, and providing psychological and economic support. For example, three participants $[\mathrm{P} 1,3$ and 6] reported that the support they received from the "association of Bezawit people living with HIV" helped them to disclose their HIV status after hearing shared experiences from peers in the association. They also commented that the support they got from the association changed their lives, both financially and in terms of reducing stigma and discrimination. However, other participants did not see a need for involvement in social networking for self-management, for example, viewing it as a waste of time because members lacked appropriate knowledge.

Another critical source of support came from friends and family members. Four of the eleven participants were entirely dependent on support from family members to carry out their medical recommendations.

Family members were helping in reducing my stress, reminding medication time and general discussion about my conditions. [P2]

Nine of the eleven participants used different strategies in the process of SM to avoid forgetting their medications, particularly reminder approaches. Some used families or friends as reminders, while others used their phone alarm. Two participants commented on the challenge of not being able to use a watch due to illiteracy, which meant they had to depend on other family members or friends to remind them of the timing of their treatment [P3 \& 8].

I am using my families as a reminder for my drug. I could not take on time my medications if they were not with me. [P10]

My friend with whom I am living helped me to cope with the HIV condition and self-manage. She always reminds me of what to do and not to do. [P3]

\section{Reliance on HIV Care Providers}

The majority of participants acknowledged the support they got from HIV care providers, particularly around health information and HIV medication, which were seen to enhance SM. The support they got from HIV care providers allowed most participants to lead a productive and healthy life; one person referring to the HIV care providers as 'my health keepers' [P4]. Notably, the information that care providers gave on participants' HIV status helped them to focus attention on SM.

Knowing my current HIV condition motivated me more to self-manage. [P3]

Knowing the condition of the disease helped me to plan for better self-management. [P11]

They told me about my CD4, whether it improved or needed improvement. It helped me to identify the problem of my self-management. Overall, knowing self-HIV status is essential for determining the focus area of weakness and strength. [P5]

However, whilst most participants thought it is essential to know their HIV status, many of them were, in fact, unaware of their specific HIV disease status, for example, concerning their CD4 level.

I do not know the level of my condition now; I forgot it; however, if I knew the level of the disease, it helps me to 
treat myself well. They [HIV care providers] better remind us every time we come, it might motivate me. [P4]

I do not know the status of my disease. [P8]

Many participants reported increased confidence to carry out SM through the process of HIV therapy. However, they also acknowledged the need for intense supervision from HIV care providers to enhance their SM. This helped to improve health status, retention in care and adherence to treatment. This was seen to be particularly important for adults living in rural communities.

Intense supervision on self-management is essential because many adults on ART do not correctly take their medication for different reasons. [P1]

\section{Acceptance of HIV}

As treatment started and their health status improved, many participants realised that accepting and living with HIV was the only option open to them. Some described living with HIV as their destiny or fate, whilst others thought that living with HIV on therapy was not that different from those who were not HIV positive.

Living with HIV does not have a new feeling. I am living as any other person is living. Now, I am delighted and leading a stable health condition. It is a sin punishment for our bad behaviour... I must accept living with HIV as part of life and be able to carry out my self-management. [P10]

The confidence developed once they started on HIV therapy enhanced the ability of participants to self-manage.

It is a matter of convincing myself. I have the confidence and power to treat myself. My self-efficacy is increasing from time to time". [P3]

\section{Availability of Free HIV Medication}

All participants described HIV medication as a lifesaver that allowed them to cope. Without the therapy, it was unimaginable to live the life they were living. Many participants reported that it had significantly impacted on their health status from a state of being bedridden to now leading productive lives. The free HIV medication enhanced engagement in SM programs.

Thanks to the free HIV treatment I got from health care providers. This support is very decisive in engaging in the treatment program. [P3]
The treatment program is for free for all, which is great support for self-managing. [P6, 7and9]

However, whilst most of the participants were motivated by the beneficial effects of the treatment program, a minority had contradictory feelings:

On one side, I thank God for keeping me healthy; on the other side life with HIV is difficult because of taking HIV medication always. [P2]

\section{Barriers to Self-Management}

From the interview data, several barriers to SM were also identified. These included financial difficulties, fear of stigma and discrimination, spiritual practice, and lack of trust in HIV care providers.

\section{Financial Difficulties}

As described in relation to attempts to remain healthy as part of SM, many participants faced financial challenges, with 8 of the 11 participants stating that their income was not sufficient to cover the cost of living. Six of the participants reported a monthly average income within the range of 120-2500ETB (equivalent to 4.30-89 USD), which is also reported insufficient to fulfil basic SM needs. Such financial hardship presents challenges in relation to supporting families, refilling medications for the treatment of opportunistic infection, costs of transportation for hospital visits and diet. As one participant commented:

It is difficult to say that I am performing my selfmanagement due to inadequate income ... my focus is on my work to generate income. Inadequate income is affecting my diet. Sometimes, I feel hungry due to a lack of food. [P1]

Another participant commented that her child was living with other family members because her income was inadequate. [P3]

\section{Fear of Stigma and Discrimination}

Many of the participants reported that they incurred additional transportation costs to receive HIV treatment from health facilities further away from where they lived even though an HIV care facility was available in their local community. This was because they did not want to be treated in their local health facilities due to fear of stigma and discrimination. This created an additional financial burden and a potential risk factor for poor SM.

This hospital is convenient for me. I do not want to be treated in my area even though I have a difficulty of 
covering my cost of transportation. I do not want to go and get treated in my area due to the presence of stigma and discrimination. [P11]

I was told to go to a health facility in my area, but I insisted on remaining here for my HIV follow up and treatment despite the challenge of the increased cost of transportation and living cost. In my community, there is a perception problem regarding the disease [HIV]. [P2]

Stigma and discrimination, especially in the rural community, were the main obstacles in the process of HIV therapy that made ALWHIV travel to distant health facilities to get treatment. Participants from rural locations claimed that the perception of the rural community was significantly influencing their SM, for example, in preferring not to disclose their HIV status or receiving treatment in their local area. Some even chose to move to live in an urban setting, although this could create further financial difficulty as they needed to rent a house to live in. The perceived fear of stigma and discrimination meant that disclosure was difficult even though participants were advised to do so.

HIV care providers told me many times to disclose my status and get treatment in nearby health facilities. I rejected this many times due to fear of stigma in my community. In the same way, working on community perception may be necessary. [P5]

Living in a rural area is challenging because of society's perception of HIV ... stigma and stigmatisation. I am thinking of living in town, and this may help me to follow my treatment. I will rent a house in a town. I am not comfortable in my living area, and I want to change to the urban area. I am getting sick from time to time. In rural areas, society thinks that the disease will be transferred through contact. [P9]

Consequently, the presence of HIV care centres in the local community has not fully solved the burden of transportation costs and access issues for all ALWHIV.

\section{Spiritual Practice}

Another self-management challenge was related to spiritual practices such as the use of holy water and fasting. For example, even if participants themselves were not fasting, their SM could be affected by the family's fasting time and practice, causing them to skip medication and diet.

The reason for not performing my self-management is my mother's fasting time; I am waiting for my mother till the end of her fasting time to eat food with her... If my medication is in the morning, it could be difficult for me. [P1]
Another participant added:

For the interest of family, I am also fasting and using holy water, and the fasting time has influenced my selfmanagement. [P7]

The study findings demonstrate a potential conflict of priorities, with participants worried about practising spiritual life and SM together.

Today is fasting day, so how can I take medication? I commented many times for missing drugs on fasting days. Spirituality is part of my life; I must think of my future spiritual life. In my age, not fasting is a sin. That is why I am not taking medications in the morning during fasting days. [P8]

\section{Lack of Trust in HIV Care Providers}

Whilst HIV care providers were identified as a key enabler of good SM, challenges were also identified, such as a sense of decreasing attention from the health care system.

Preventing the progression and stopping HIV spread has got less attention compared to the past and made me hopeless. Many of my friends are leaving their medication. Strong counselling and tracing should be in place. [P5]

Other participants commented that their HIV care providers looked bored, which affected their level of trust in the treatment program [P5 \& 7]. It was also reported that the emphasis on counselling and tracing had reduced, which impacted on SM.

I got counselling services from HIV care providers regarding my HIV treatment and on the importance of joining peers. However, I do not believe that the counselling service is enough. [P1]

\section{Summary of Findings}

Participants mostly associated SM with taking medication and staying healthy through the practice of physical activities and diet management. SM was enhanced by systems such as adherence supporters, social networking, and family supports, supervision from HIV care providers and availability of free medication. Major barriers to effective SM included financial difficulties, fear of stigma and discrimination, spiritual beliefs and practice and, in some instances, a lack of trust in HIV care providers. These issues are explored further in the discussion. 


\section{Discussion}

This study examined the SM experience and influencing factors among ALWHIV on ART in Northwest Ethiopia. In line with the IFSMT, the findings reveal a number of interconnected and often reinforcing factors that pose challenges to maintaining effective self-management amongst ALWHIV on therapy. These relate to the potential conflict between the requirements of SM and spiritual beliefs and practice, the difficulties of maintaining a healthy lifestyle on low levels of income and the impacts of experiencing stigma and discrimination.

Orthodox Christianity is the dominant religion in Ethiopia and one that involves regular fasting to fulfil religious obligations. This involves fasting until lunchtime on Wednesday and Friday every week and a full 15 to 56-day block of fasting during the fasting seasons. Similarly, going to monasteries to fast and use holy water is a major reason for skipping medication and diet or even stopping medical treatment. As a result, skipping medication and diet during fasting time and the use of holy water was common, supporting the findings from a previous study conducted in Ethiopia. ${ }^{15}$ From the perspective of the IFSMT, the conflict between spiritual practice and taking treatment offers a specific example of goal incongruence and highlights an important area for action, namely working with religious leaders to educate ALWHIV on ways of reconciling medical recommendations and religious practice.

Financial difficulties, related to low levels of income, created a number of challenges, including the ability to maintain a healthy diet and a pressure to work, which limited the ability to get adequate rest and relaxation. In turn, these factors could add to feelings of stress. Financial difficulty is globally recognised as a major challenge affecting SM. ${ }^{12,14,18,19,25}$ However, in our study, issues related to stigma and discrimination added another layer of stress and financial burden. For example, in rural areas, stigma and discrimination forced some people to travel outside their community for treatment, creating additional transportation costs and exacerbating financial difficulties. The fear of stigma and discrimination also affected the willingness to disclose HIV status, thus limiting the potential to share experiences with others and mobilise existing resources from the community. This affected the involvement of ALWHIV in community networking in our study area, which is recognised as an important support strategy in existing literature. ${ }^{11,14,21}$ Working to minimise the perception of stigma and discrimination, particularly in rural areas, is an essential aspect of HIV care and an important pre-requisite to encouraging disclosure of HIV status.
Despite the challenges and barriers, the study identified various strategies that could help to enhance selfmanagement. Consulting with HIV care providers, sharing experiences within social networks and being familiar with symptom management enhanced the experience of SM, a finding that is consistent with other studies, ${ }^{6,26}$ including research conducted in Uganda and the USA. ${ }^{4}$ Participation in social networking can help ALWHIV to get access to health information, resources and share lived experience with individuals with the same condition. As such, establishing networks of ALWHIV and promoting their engagement in networking could be helpful. Along similar lines, the findings also identified that the presence of adherence supporters facilitated SM behaviours, which is consistent with a study conducted in Uganda. ${ }^{10}$ The use of adherence supporters in resourcelimited settings can serve a dual purpose. Firstly, it helps to support the sharing of lived experiences, for example, how to cope with medication side effects, symptom management and the need to follow a strict medication regime, since adherence supporters are also ALWHIV on therapy. Secondly, it represents a job opportunity for ALWHIV on therapy and can motivate others to engage in SM behaviours more actively. However, the feasibility and effectiveness of these type of enabling strategies is dependent upon prior attention to the previously identified barriers to disclosure. This poses an important question about where to start in terms of strategies to facilitate and support more effective SM, for example, by considering which of the identified barriers are potentially the most modifiable and how best to address them.

Of the previously discussed barriers, namely the conflict between spiritual practice and SM activities, financial constraints and stigma and discrimination, tackling issues relating to stigma and discrimination could help to alleviate some of the other problems experienced and would seem to be an appropriate starting point. For example, if ALWHIV felt comfortable to receive care closer to home, they would not incur the additional transportation costs associated with visiting an HIV clinic further away. They might also feel able to more openly discuss the tensions they experience between maintaining established spiritual practice, such as fasting, and the need to follow a strict medication regimen.

HIV providers are an important group to consider in terms of addressing the barriers presented by stigma and discrimination. Consistent with a study conducted in Uganda, ${ }^{9}$ HIV care providers were considered as important health keepers, acting as a resource for health information, providing practical advice on SM, encouraging disclosure and linking with other support groups. On the contrary, however, some participants expressed 
negative views, perceiving some care providers to be less engaged or attentive, suggesting a possible need to invest in staff education and resources. Specific activities that health care providers could undertake include increasing the individual's own awareness of their HIV status, such as their CD4 count, as this type of feedback could reinforce the motivation to self-manage. However, more intensive information provision and support on an individualised basis during follow-up visits could have implications for the number of HIV care providers required to staff the HIV clinics.

Our study identified the significance of supervision to enhance engagement in the SM program, especially for those with low educational literacy and those living in rural communities. The finding is supported by previous research. ${ }^{8,9}$ Low literacy and living in rural communities could be linked to poor SM behaviour due to various reasons, including the inadequacy of health information, poor communication infrastructure, and fear of stigma and discrimination. As a result, ALWHIV require persistent supervision from HIV care providers could help them to keep doing what is recommended.

In summary, the study highlights the complexities involved in attempting to improve the SM behaviour of ALWHIV in Ethiopia, influenced by specific economic, social and cultural factors. A number of key findings emerge that require the critical attention of HIV care providers and policymakers. Firstly, the interconnectedness of the various contextual factors adds to the complexity of improving SM experience. For example, those living in a rural community are more likely to experience stigma and discrimination and so choose to travel further away for treatment. However, the costs associated with this exacerbate their financial difficulties and could have a knock-on effect in terms of the ability to maintain a healthy diet and managing stress, consequently making SM even more difficult to achieve. Fear of stigma and discrimination is also an issue influencing attitudes to disclosure, in turn affecting resource mobilisation and poorer SM. Therefore, decreasing fear of stigma and discrimination should be a primary area for interventions to enhance SM of ALWHIV. However, encouraging individual disclosure alone is not a solution; rather, working on the community's broader perception about HIV is essential. This includes taking account of the prevailing religious culture and the potential conflict between spiritual beliefs and effective SM behaviour, an area where local religious leaders may have an important role to play in community education and support. Finally, the role played by HIV care providers and adherence supporters in the provision of health information, supervision, and coping is vital and one that should be intensified and developed moving forward.

In terms of limitations, it is important to note that the study was conducted on participants from one regional area in Ethiopia and all shared the same cultural and religious background. This might affect the transferability of the findings beyond the immediate study setting.

\section{Conclusions}

This study highlights the particular challenges faced by individuals living with HIV on antiretroviral therapy in a resourceconstrained country. Whilst some barriers to effective SM require long-term solutions, for example, poverty and low levels of literacy, the study also identifies a number of modifiable barriers where actions in the short to medium term could enhance SM practice. This will require a collaborative effort from a range of stakeholders, including HIV care providers, policymakers, and health system and religious leaders.

\section{Abbreviations}

ALWHIV, adults living with HIV; HIV, human immunodeficiency virus; IFSMT, Individual and Family SelfManagement Theory; SM, self-management.

\section{Data Sharing Statement}

Data supporting the findings of this study are available from the corresponding author [HA] on request.

\section{Ethical Considerations}

All procedures performed in this study were in accordance with the 1964 Helsinki declaration and its later amendments or comparable ethical standards. Ethical approval for the study was obtained from the University of Adelaide (H-2018-243) and Amhara Regional Health Bureau Research Office (APHHRTD/03/264/2019). Written informed consent was obtained from all individuals participants included in the study.

\section{Consent for Publication}

Consent for publication was obtained from all participants, including consent to publish anonymized quotes from the interview in published material.

\section{Acknowledgments}

The authors would like to thank the study participants and HIV care providers for their facilitation during data collection. 


\section{Author Contributions}

All authors made substantial contributions to conception and design, acquisition of data, or analysis and interpretation of data; took part in drafting the article or revising it critically for important intellectual content; agreed to submit to the current journal; gave final approval of the version to be published; and agree to be accountable for all aspects of the work.

\section{Funding}

The University of Adelaide, Adelaide Nursing School, supported the study by providing a $\mathrm{PhD}$ stipend to the first author. The funder was not involved in study design, data collection, analysis, interpretation of the result, and decision to publish.

\section{Disclosure}

The authors report no conflicts of interest in this work.

\section{References}

1. Ethiopian HIV \& AIDS statistics — 2019 fact sheet 2020. https:// www.unaids.org/en/regionscountries/countries/ethiopia. Accessed December 7, 2019.

2. EMOH. Country/Regional Operational. Plan: Strategic Direction Summary. Addis Ababa: Ministry of Health; 2017:5-12.

3. Swendemana D, Ingramb BL, Rotheram-Borusa MJ. Common elements in self-management of HIV and other chronic illnesses: an integrative framework. AIDS Care. 2009;21(10):1321-1334. doi:10.1080/09540120902803158

4. Schulman-Green D, Jaser S, Martin F, et al. Processes of Self-management in chronic illness. J Nurs Scholarship. 2012;44 (2):136-144. doi:10.1111/j.1547-5069.2012.01444.x

5. Ryan P, Sawin KJ. The individual and family self-management theory: background and perspectives on context, process, and outcomes. Nurs Outlook. 2009;57(4):217-225. doi:10.1016/j.outlook.2008.10.004

6. Martin F, Kiwanuka T, Kawuma R, Zalwango F, Seeley J. Tasks and strategies of self-management of living with antiretroviral therapy in Uganda. AIDS Patient Care STDS. 2013;27(12):697-706. doi:10.1089/ apc.2013.0254

7. Areri HA, Marshall A, Harvey G. Interventions to improve self-management of adults living with HIV on antiretroviral therapy: a systematic review. PLoS One. 2020;15(5):e0232709. doi:10.1371/ journal.pone.0232709

8. Holtzman CW, Brady KA, Yehia BR. Retention in care and medication adherence: current challenges to antiretroviral therapy success. Drugs. 2015;75(5):445-454. doi:10.1007/s40265-015-0373-2

9. Russell S, Zalwango FM, et al. Finding meaning: HIV self-management and wellbeing among people taking antiretroviral therapy in Uganda. PLoS One. 2016;11(1):e0147896. doi:10.1371/journal.pone.0147896
10. Nakamanya S, Mayanja BN, Muhumuza R, Bukenya D, Seeley J. Are treatment supporters relevant in long-term Antiretroviral Therapy (ART) adherence? Experiences from a long-term ART cohort in Uganda. Glob Public Health. 2019;14(3):469-480. doi:10.1080/ 17441692.2018.1514418

11. Wang K, Chen WT, Lin Z, Bao M, Zhao H, Lu H. Facilitators of and barriers to HIV self-management: perspectives of HIV-positive women in China. Appl Nurs Res. 2016;32:91-97. doi:10.1016/j.apnr.2016.06.004

12. Webel AR, Dolansky MA, Henry AG, Salata RA. A qualitative description of women's HIV self-management techniques: context, strategies, and considerations. J Assoc Nurses AIDS Care. 2012;23 (4):281-293. doi:10.1016/j.jana.2011.09.002

13. Sullivan KM, Inouye J. Feasibility of a group-based self-management program for ethnically diverse people with HIV/AIDS in Hawaii. Asian Pac Island Nurs J. 2015;1:1.

14. Anna G. A Comparative Study of the Barriers to HIV Self-Management Among Myanmar Migrant and Han Chinese Women in Yunnan, China. Independent Study Project (ISP) Collection; 2017:2736.

15. Bezabhe WM, Chalmers L, Bereznicki LR, Peterson GM, Bimirew MA, Kassie DM. Barriers and facilitators of adherence to antiretroviral drug therapy and retention in care among adult HIV-positive patients: a qualitative study from Ethiopia. PLoS One. 2014;9(5):e97353. doi:10.1371/journal.pone.0097353

16. Tiruneh YM, Wilso IB. What Time is it? Adherence to antiretroviral therapy in Ethiopia. AIDS Behav. 2016;20(11):2662-2673. doi:10.1007/s10461-016-1322-0

17. Adefolalua A, Nkosia Z, Olorunjub S, Masemola P. Self-efficacy, medication beliefs and adherence to antiretroviral therapy by patients attending a health facility in Pretoria. South Afr Fam Pract. 2014;56(5):1-5.

18. Wasti SP, van Teijlingen E, Simkhada P, et al. Factors influencing adherence to antiretroviral treatment in Asian developing countries: a systematic review. Trop Med Int Health. 2012;17(1):71-81. doi:10.1111/j.1365-3156.2011.02888.x

19. Johnston S, Liddy E, Ives S,M. Self-management support: a new approach still anchored in an old model of health care. Can J Public Health. 2011;102(1):68-72. doi:10.1007/BF03404881

20. Oskouie F, Kashefi F, Rafii F, Gouya MM. Barriers to self-care in women of reproductive age with HIV/AIDS in Iran: a qualitative study. Pan Afr Med J. 2017;28:231. doi:10.11604/pamj.2017.28.231.12385

21. McDonald K, Slavin S, Pitts MK, Elliott JH. Chronic disease self-management by people with HIV. Qual Health Res. 2016;26 (6):863-870. doi:10.1177/1049732315600415

22. Areri HA, Marshall A, Harvey G. Factors influencing self-management of adults living with HIV on Antiretroviral Therapy in North West Ethiopia: a cross-sectional study. $B M C$ Infect Dis [Under Review]. 2020.

23. Polit DF, Beck CT. Nursing Research: Generating and Assessing Evidence for Nursing Practice. 9th ed. Philadelphia: Lippincott, Williams \& Wilkins; 2012.

24. Braun V, Clarke V. Using thematic analysis in psychology. Qual Res Psychol. 2006;3(2):77-101. doi:10.1191/1478088706qp063oa

25. Wang H, Chen AC, Wan S, Chen H. Status and associated factors of self-management in people living with HIV/AIDS in Liangshan area, China: a cross-sectional study. Patient Prefer Adherence. 2019;13:863-870. doi:10.2147/PPA.S203799

26. Webel AR, Cuca Y, Okonsky JG, Asher AK, Kaihura A, Salata RA. The impact of social context on self-management in women living with HIV. Soc Sci Med. 2013;87:147-154. 
HIV/AIDS - Research and Palliative Care

\section{Publish your work in this journal}

HIV/AIDS - Research and Palliative Care is an international, peerreviewed open-access journal focusing on advances in research in HIV, its clinical progression and management options including antiviral treatment, palliative care and public healthcare policies to control viral spread. The manuscript management system is completely online and includes a very quick and fair peer-review system, which is all easy to use. Visit http://www.dovepress.com/testimonials.php to read real quotes from published authors.

Submit your manuscript here: https://www.dovepress.com/hivaids—research-and-palliative-care-journal 